\title{
Hypervolemia for Hypertension Pathophysiology: A Population-Based Study
}

\section{Ender Hür, ${ }^{1}$ Melih Özişik, ${ }^{2}$ Cihan Ural, ${ }^{2}$ Gürsel Yildiz, ${ }^{3}$ Kemal Mağden, ${ }^{1}$ Sennur Budak Köse, ${ }^{4}$ Füruzan Köktürk, ${ }^{5}$ Çağatay Büyükuysal, ${ }^{5}$ İbrahim Yildirim, ${ }^{1}$ Gülttekin Süileymanlar, ${ }^{6}$ Kenan Ateş, ${ }^{7}$ and Soner Duman ${ }^{2}$}

${ }^{1}$ Division of Nephrology, Bülent Ecevit University, Zonguldak, Turkey

${ }^{2}$ Department of Internal Medicine, Ege University, Izmir, Turkey

${ }^{3}$ Nephrology Clinic, Ataturk State Hospital, Zonguldak, Turkey

${ }^{4}$ Nephrology Clinic, Istanbul Education and Research Hospital, Istanbul, Turkey

${ }^{5}$ Department of Biostatistics, Bülent Ecevit University, Zonguldak, Turkey

${ }^{6}$ Division of Nephrology, Akdeniz University, Antalya, Turkey

${ }^{7}$ Division of Nephrology, Ankara University, Ankara, Turkey

Correspondence should be addressed to Gürsel Yildiz; drgursel@yahoo.com

Received 5 February 2014; Revised 26 June 2014; Accepted 30 June 2014; Published 11 August 2014

Academic Editor: Abbas Dehghan

Copyright (C) 2014 Ender Hür et al. This is an open access article distributed under the Creative Commons Attribution License, which permits unrestricted use, distribution, and reproduction in any medium, provided the original work is properly cited.

Objectives. Hypertension and hypervolemia relationship was proven among renal disease, although it is not known in normal population. Present study determines the fluid distribution defects in relation to blood pressure. Material and Methods. In a population-based survey in Turkey demographics, height, weight, blood pressure, urine analysis, and serum creatinine measurements were recorded. Bioimpedance measured with the Body Composition Monitor. Results. Total 2034 population of $71.6 \%$ male, mean age $47 \pm 12.6$ (18-89) years, systolic blood pressure (SBP) $134.7 \pm 20$, diastolic blood pressure $77.9 \pm 11.6 \mathrm{mmHg}$. Body mass index $(\mathrm{BMI})$ was $28.5 \pm 4.5(15.8-50.6) \mathrm{kg} / \mathrm{m}^{2}$; overhydration was $0.05 \pm 1.05 \mathrm{~L}$. There was a correlation between extracellular water (ECW)/height and SBP $(r=0.21, P<0.001)$. Receiver operating characteristic (ROC) curve with the performance of $0.60(P<0.001)$ that showed cut-off value of ECW/height was $10.06 \mathrm{~L} / \mathrm{m}$, with the $69 \%$ sensitivity and $45 \%$ specificity for SBP: $140 \mathrm{mmHg}$ values. Risk factors for high SBP were increase of ECW/Height, age, BMI and presence of diabetes. ECW/height, SBP, and fat tissue index (FTI) increased in BMI categories (low, normal, and obese) and in diabetics. SBP and FTI were lower in smokers. Conclusions. High blood pressure may be accompanied by increased extracellular volume indices. In the future volume status assessment could be of use in evaluating the effectiveness of pharmacological intervention in the treatment of hypertension.

\section{Introduction}

Hypertension is one of the most important health problems in the world. The mortality and morbidity are related to the severity and duration; therefore, early diagnosis and treatment provide favorable clinical outcome. It has been proposed that abnormal ion transport by the kidney and subsequent disruption of body fluid volumes are responsible for the development of hypertension [1].

Etiology has been defined in only $5 \%$ of hypertensive subjects, while the essential hypertension is the classification in the majority of subjects meaning that no clear underlying cause can be found. Up to now obtaining data about body fluids have many difficulties; therefore, studies performed in this field were in small size and related to a specific disease group [2]. It is not known if these body fluid changes represent the cause or rather the effect of hypertension. Clarifying the relation of body fluid and blood pressure rise in a population study could offer new therapeutic approaches with remarkable impact on this affection.

In bioimpedance spectroscopy (BIS), complex impedance is measured over a wide range of frequencies and the data 
are fit to a well-known model of biological tissue. The extracellular and intracellular resistance are obtained by Cole model $[3,4]$. Total body water (TBW) is the sum of ECW + ICW. The basis of BIS is that at low frequency (zero) current, there is no conduction through biological cells and only the ECW is measured and at high frequency (infinite), both the ECW and ICW are fully measured.

A new tool (FMC BCM) (based on plausible scientific principles) has been introduced to the medical field that allows the ECW and ICW (and overhydration) to be measured routinely with reasonable accuracy for the first time in history. This tool has revealed that significant overhydration $(\mathrm{OH})$ is present in $30 \%$ of European HD and PD patients [5] and a strong predictor of LV hypertrophy and mortality $[6,7]$. It has also been found that BP is a poor predictor of $\mathrm{OH}$ during heart failure [8]. The obvious next step is to study the general population with this new tool.

Aim of this epidemiologic study is to determine the assessment of body fluids and the estimation of the compartmental distribution in ICW and ECW via BIS in a healthy population and their relation to blood pressure. It is the first study to show the compartmental distribution defects with relation to blood pressure in such a large population.

\section{Subjects and Methods}

2.1. Study Design. We performed a population-based, national survey in Turkey on population aged over 18 years. All subjects included in this survey gave informed consent to participate in the field study. Exclusion criteria were the presence of pacemaker or defibrillator, artificial joints, pin, or amputation; presence of serious life-limiting comorbid situations, like malignancy; uncontrollable infection; endstage cardiac, pulmonary, or hepatic disease; and pregnancy or lactating.

The study was approved by Turkish Ministry of Health and was conducted in accordance with ethical principles of the Declaration of Helsinki; all patients provided written inform consent.

2.2. Sampling Method. A random sampling was used to select the study participants. A sampling frame was defined as the five official geographical regions of Turkey. The study sample comprised 17 cities including both the city with the highest population and a randomly selected city with a low population in each geographical area.

2.3. Field Study. The data were collected through Turkish Population Renal Health Screening Programme organized by Turkish Society of Nephrology. Measurements and interviews of potential participants by specially trained field study teams (medical doctors, nurses, laboratory technicians). During interviews, the study questionnaire included questions on subject demographics current diseases and drugs, family history, and other relevant medical history. In addition, height, weight, and blood pressure were measured. Blood pressure was measured from right arm in sitting position.
Bioimpedance measurements were performed in supine position by a trained medical doctor.

2.4. Laboratory Assessment. Spot urine analysis (by dipsticks) was performed before BCM measurement, and results were recorded on the study questionnaire. Urinary measurements were excluded in menstruating women and in all patients suffering from febrile illness [9]. Serum creatinine (alkaline picrate method) was used. Assessing proteinuria from a test strip was carried out using the Combur Test M system with an automatic reading given by a Miditron M (Roche Diagnostics) urinalysis system.

2.5. Measurement of Overhydration. After measurement of body weight and height and with subjects following voiding, bioimpedance spectroscopy (BIS) was measured with the Body Composition Monitor (BCM) from Fresenius Medical Care, Deutschland GmbH. Four electrodes were placed on the right hand and foot on the side contralateral to the arteriovenous fistula, of supine patients. Two electrodes were dorsally placed on the hand in the metacarpophalangeal articulations and in the corpus, respectively, $5 \mathrm{~cm}$ apart. The pair on the foot was located in the metatarsophalangeal and in the articulation, $6 \mathrm{~cm}$ apart. The BCM analyses total body electrical impedance to an alternate current $(0.2 \mathrm{~mA})$ with fifty different frequencies $(5-1000 \mathrm{kHertz})$. First the ECW, ICW, and total body water are calculated via determining electrical resistances. Then values of $\mathrm{OH}$, body mass index, lean tissue index, fat tissue index, and body cell mass are provided by the BCM software [3].

The reference ranges are defined by the 10th and 90th percentiles of the reference population and are specific to age and gender [3].

2.6. Definitions. Serum creatinine levels, estimated GFR, and spot urine microalbuminuria were studied as markers for kidney function. CKD was defined as kidney damage with or without a decrease in GFR, which was calculated using a simplified version of the Modification of Diet in Renal Disease $(\mathrm{MDRD})$ formula $[186 \times(\mathrm{Scr})-1.154 \times($ Age $)-$ $0.203 \times(0.742$ if woman $) \times(1.212$ if African American $)$ [ [10] Since there were no African American subjects in our study population, the last variable of the formula was not used.

The fluid volumes extracellular (ECW), intracellular (ICW), and total body water (TBW) were determined using the approach described by Moissl et al. [3]. The hydration status, lean tissue mass (LTM), and fat mass were calculated based on a physiologic tissue model described by Chamney et al. [4]. LTM and Fat were normalized to the body surface area to obtain lean tissue index (LTI $=\mathrm{LTM} /$ height $\left.^{2}\right)$ and fat tissue index $\left(\mathrm{FTI}=\mathrm{Fat} /\right.$ height $\left.^{2}\right)$. The values for LTI and FTI were compared to an age- and gender-matched reference population $(n=1248)$ [11].

Body mass index (BMI) was calculated as weight $(\mathrm{kg}) /$ height $\left(\mathrm{m}^{2}\right)$.

Hydration reference plot. By combining measurements of $\mathrm{OH}$ and SBP, a normal healthy population reference region (N) was established as SBP 100-140 mmHg, OH (-1.1)-(1.1) L. 
Region Dx. SBP 100-150 mmHg and a typical weight gain of $(-1.1)-(2.5) \mathrm{L}$. The selection of $2.5 \mathrm{~L}$ is completely arbitrary.

Region I. This region represents patients with a $\mathrm{OH}>2.5 \mathrm{~L}$ and an increased SBP $>140 \mathrm{mmHg}$. There is a high likelihood that hypertension in these patients is indicative of the gross $\mathrm{OH}$ observed.

Region I-II. This represents a population with mild elevation of - $\mathrm{OH}$ between 1.1 and $2.5 \mathrm{~L}$ concomitant with an increased SBP > $150 \mathrm{mmHg}$.

Region II. This represents patients in a state of normohydration, but SBP > $150 \mathrm{mmHg}$. Patients in this region are clearly hypertensive, but there is far less likelihood that volume is a contributing factor.

Region III. It characterises underhydrated patients with normal or low $\mathrm{SBP}<140 \mathrm{mmHg}$.

Region $I V$. This represents patients with gross $\mathrm{OH}, \mathrm{OH}>$ $2.5 \mathrm{~L}$, and a normal or low SBP $\leq 140 \mathrm{mmHg}$. In this patient population, the gross $\mathrm{OH}$ is not reflected in SBP [8].

2.7. Statistical Analysis. Statistical analysis was performed with SPSS 18.0 software (SPSS, Inc., Chicago, IL, USA). Continuous variables were expressed as mean \pm standard deviation and categorical variables as numbers and percentages. Continuous variables were compared with the Independent Sample $t$-test or Mann-Whitney $U$ test and categorical variables were compared using Pearson's Chisquare test. Pearson and Spearman correlations were used for the linear relation between two numerical dates. Receiver operating curve (ROC) analysis was used for the detection of cut-off values. Binary logistic regression analysis with forward stepwise method was used for determination of risk factors. $P$ value of less than 0.05 was considered statistically significant for all tests.

\section{Results}

Study cases were aged between 18 and 89, with the mean of $47 \pm 12.6$ years. Characteristics of the study population were given in Table 1 .

Mean BCM measurement quality given by the device itself was $93.22 \pm 4.6$ percent; measurement duration was $69.2 \pm 33.6$ seconds.

Mean systolic blood pressure (SBP) was $134.7 \pm 20.0$, and diastolic blood pressure was (DBP) $77.9 \pm 11.6 \mathrm{mmHg}$. BMI was $28.5 \pm 4.5(15.8-50.6) \mathrm{kg} / \mathrm{m}^{2}$, body surface area (BSA) was $1.89 \pm 0.17(1.33-2.47) \mathrm{m}^{2}, \mathrm{OH}(\mathrm{L})$ was $0.05 \pm 1.05 \mathrm{~L}$, $\mathrm{OH} / \mathrm{ECW}(\%)$ was $0.01 \pm 5.94, \mathrm{ECW} /$ height was $10.46 \pm$ $1.36 \mathrm{~L} / \mathrm{m}$, TBW (L) was $39.9 \pm 6.6, \mathrm{ECW}(\mathrm{L})$ was $17.6 \pm 2.79$, ICW $(\mathrm{L})$ was $22.3 \pm 4.15$, LTI $\left(\mathrm{kg} / \mathrm{m}^{2}\right)$ was $16.3 \pm 2.85$, FTI $\left(\mathrm{kg} / \mathrm{m}^{2}\right)$ was $11.9 \pm 5.3$, adipose tissue mass (ATM) was $32.82 \pm 13.32 \mathrm{~kg}$, lean tissue mass (LTM) was $46.44 \pm$ $10.63 \mathrm{~kg}$, and body weight was $79.2 \pm 13 \mathrm{~kg}$.

There was a weak positive correlation between ECW/ height and SBP $(r=0.21, P<0.001)$. There were a strong correlation between BMI and FTI $(r=0.82, P<0.001)$,
TABLE 1: Characteristics of the study population $(n=2034)$.

\begin{tabular}{lc}
\hline & $n(\%)$ \\
\hline Gender & $1456(71.6)$ \\
Male & $578(28.4)$ \\
Female & \\
Age groups & $1870(91.9)$ \\
$<65$ & $164(8.1)$ \\
$\geq 65$ & \\
Geographical region & $323(15.9)$ \\
Central Anatolia & $141(6.9)$ \\
Mediterranean & $578(28.4)$ \\
Aegean & $626(30.8)$ \\
East Anatolia & $366(18)$ \\
Southeastern Anatolia & \\
Measurement time & $649(31.9)$ \\
Morning $(<12$ o'clock) & $1385(68.1)$ \\
Afternoon $(\geq 12$ o'clock) & \\
Disease history & $1250(61.5)$ \\
Healthy & $240(11.8)$ \\
Diabetics & $380(18.7)$ \\
Known HT & $87(4.3)$ \\
CAD & $41(2)$ \\
COPD & $47(2.9)$ \\
CKD & \\
Anti-HT & $96(4.7)$ \\
ACEi/ARB & $50(2.5)$ \\
Beta blockers & $18(0.9)$ \\
CCB & $7(0.3)$ \\
Diuretics & \\
\hline
\end{tabular}

The number of subjects is crude (unadjusted) figures.

HT: hypertension, CAD: coronary artery disease, COPD: chronic obstructive pulmonary disease, CKD: chronic kidney disease, ACEi: angiotensin converting enzyme inhibitors, ARB: angiotensin receptor blockers, and CCB: calcium channel blockers.

correlation even more pronounced among females $(r=0.93$, $P<0.001$ ), whereas no correlation between BMI and LTI in both genders but a weak positive correlation in male group $(r=0.16, P<0.001)$. There was a negative correlation between eGFR and ECW/Height $(P=0.024, r=-0.06)$.

Age, BMI, ECW/height, and BSA increased significantly in normotensives than hypotensives and even increased in hypertensives than in both normotensives and hypotensives. FTI was higher in hypertensives than in both normotensives and hypotensives. Smoking rate was lower in hypertensives compared to normotensives (Table 2).

There was a statistical significance in relation to diabetes, smoking habits, and measurement time (whether morning or afternoon) in relation to SBP. In $52.5 \%$ of diabetics and $25.8 \%$ of cigarette smokers, $32.1 \%$ of afternoon measurements had $\mathrm{SBP} \geq 140 \mathrm{mmHg}$, and in $68.2 \%$ of nondiabetics and $64.9 \%$ of nonsmokers, $61.2 \%$ of morning measurements had SBP $<$ $140 \mathrm{mmHg}(P<0.05)$.

Risk factors for high SBP were increase of ECW/height, age, and BMI and presence of diabetes (Table 3). ECW/height 
TABLE 2: Univariate analysis of systolic blood pressure categories.

\begin{tabular}{|c|c|c|c|}
\hline Variables & $\begin{array}{c}\text { Hypotensives } \\
(\mathrm{SBP}<110 \mathrm{mmHg}) \\
(n=133)\end{array}$ & $\begin{array}{c}\text { Normotensives } \\
(140>\mathrm{SBP} \geq 110 \mathrm{mmHg}) \\
(n=1208)\end{array}$ & $\begin{array}{c}\text { Hypertensives } \\
(\mathrm{SBP} \geq 140 \mathrm{mmHg}) \\
(n=693)\end{array}$ \\
\hline BMI $\left(\mathrm{kg} / \mathrm{m}^{2}\right)$ & $26.38 \pm 4.98$ & $27.59 \pm 4.39 \mathrm{a}$ & $29.49 \pm 4.23 \mathrm{a}^{*} \mathrm{~b}^{*}$ \\
\hline ECW/height $(\mathrm{L} / \mathrm{m})$ & $9.93 \pm 1.58$ & $10.34 \pm 1.32 \mathrm{a}^{*}$ & $10.78 \pm 1.32 \mathrm{a}^{*} \mathrm{~b}^{*}$ \\
\hline Age & $41.47 \pm 11.69$ & $44.36 \pm 12.38 \mathrm{a}$ & $52.84 \pm 11.23 \mathrm{a}^{*} \mathrm{~b}^{*}$ \\
\hline $\mathrm{DM}$ & $0.06 \pm 0.24$ & $0.09 \pm 0.28$ & $0.18 \pm 0.39 \mathrm{a}^{*} \mathrm{~b}^{*}$ \\
\hline Smoking & $0.16 \pm 0.37$ & $0.16 \pm 0.37$ & $0.11 \pm 0.31 \mathrm{~b}$ \\
\hline FTI $\left(\mathrm{kg} / \mathrm{m}^{2}\right)$ & $10.46 \pm 5.12$ & $11.22 \pm 5.26$ & $13.23 \pm 5.14 \mathrm{a}^{*} \mathrm{~b}^{*}$ \\
\hline $\operatorname{BSA}\left(\mathrm{m}^{2}\right)$ & $1.82 \pm 0.19$ & $1.88 \pm 0.17 \mathrm{a}^{*}$ & $1.91 \pm 0.16 \mathrm{a}^{*} \mathrm{~b}^{*}$ \\
\hline TBW (L) & $38.10 \pm 7.14$ & $39.88 \pm 6.56 \mathrm{a}$ & $40.29 \pm 6.64 \mathrm{a}^{*}$ \\
\hline $\mathrm{OH}(\mathrm{L})$ & $0.09 \pm 1.09$ & $0.03 \pm 1.01$ & $0.07 \pm 1.11$ \\
\hline
\end{tabular}

$P<0.05$; a: group versus hypotensives; b: group versus normotensives; ${ }^{*} P<0.001$.

SBP: systolic blood pressure, BMI: body mass index, ECW: extracellular water, DM: diabetes mellitus, FTI: fat tissue index, BSA: body surface area, TBW: total body water, and $\mathrm{OH}$ : overhydration.

TABLE 3: Logistic regression analysis for "high systolic blood pressure."

\begin{tabular}{lccc}
\hline Variables & Odds ratio & $95 \%$ CI & $P$ value \\
\hline DM & 1.581 & $1.177-2.124$ & 0.002 \\
ECW/height & 1.104 & $1.003-1.215$ & 0.043 \\
BMI & 1.058 & $1.027-1.090$ & 0.000 \\
Age & 1.053 & $1.043-1.063$ & 0.000 \\
\hline
\end{tabular}

DM: diabetes mellitus, ECW: extracellular water, BMI: body mass index, and CI: confidence interval. In model: OH/ECW, E/I, TBW, ECW/height, age, gender, BMI, LTI, FTI, DM, time, and smoking.

$7.71 \pm 0.87,10.1 \pm 1.17,11.32 \pm 1.28 \mathrm{~L} / \mathrm{m}$, FTI $4 \pm 2.2$ $9.5 \pm 3.5,17.1 \pm 4.7 \mathrm{~kg} / \mathrm{m}^{2}$ and SBP $120 \pm 17,132 \pm 19$, $140 \pm 21 \mathrm{mmHg}$, increased in as BMI increased (low, normal and obese), respectively, $(P<0.001)$ (Figure 1). ECW/height of $10.81 \pm 1.24$ and $10.41 \pm 1.37 \mathrm{~L} / \mathrm{m}$, FTI of $14.7 \pm 5.8$ and $11.5 \pm 5.1 \mathrm{~kg} / \mathrm{m}^{2}$, and SBP of $144 \pm 22$ and $133 \pm 19 \mathrm{mmHg}$ increased in diabetics compared to nondiabetics $(P<0.001)$ (Figure 2). ECW/height of $10.44 \pm 1.29$ and $10.47 \pm 1.37 \mathrm{~L} / \mathrm{m}$ $(P>0.05)$, FTI of $9.5 \pm 4.112 .3 \pm 5.4 \mathrm{~kg} / \mathrm{m}^{2}(P<0.001)$, SBP of $131 \pm 18,9.5 \pm 4.1$, and $135 \pm 20 \mathrm{mmHg}(P<0.001)$ were lower in smokers than in nonsmokers (Figure 3 ).

Mean overhydration $(\mathrm{OH})$ measured in the afternoon was more than morning measurements $(0.0957 \pm 1.03963$ versus $-0.0584 \pm 1.06571,(P=0.001))$.

Receiver operating characteristic (ROC) curve with the performance of $0.60(P<0.001)$ that showed cut-off value of ECW/height was $10.06 \mathrm{~L} / \mathrm{m}$, with the $69 \%$ sensitivity and $45 \%$ specificity for SBP: $140 \mathrm{mmHg}$ values.

According to hydration reference plot, there were 12 (0.6\%) cases in Region 1, 405 (19.9\%) in Region 2, 164 (8.1\%) in Region 3, 22 (1.1\%) in Region 4, 1431 (51.4\%) in DX, and 1047 (51.4\%) in Normal region (Figure 4). All cases were compared with DX region; in Region 1 there were no cases with CAD and increased incidence of DM 33.3\% $(P<$ 0.05). In Region 2 increased incidence of DM and CAD and increased BMI $\left(20.3 \%, 7.7 \%\right.$ and $29.7 \mathrm{~kg} / \mathrm{m}^{2}$, resp. $)(P<$
TABLE 4: Comorbidities according to hydration reference plot.

\begin{tabular}{lcccc}
\hline $\begin{array}{l}\text { Hydration } \\
\text { reference plot } \\
\text { regions }\end{array}$ & BMI (median) & DM (\%) & CAD (\%) & CKD (\%) \\
\hline $1(n=12)$ & $30(24.8-36.5)$ & $33.3 \mathrm{a}$ & $0 \mathrm{a}^{*}$ & 9.1 \\
$2(n=405)$ & $29.7(18.1-41.6) \mathrm{a}^{*}$ & $20.3 \mathrm{a}^{*}$ & $7.7 \mathrm{a}^{*}$ & 4.6 \\
$3(n=164)$ & $28.6(18.3-50.6) \mathrm{a}^{*}$ & 6.71 & 2.4 & 0 \\
$4(n=22)$ & $26.9(17.5-36.9)$ & 18.2 & $13.6 \mathrm{a}^{*}$ & 0 \\
DX $(n=1431)$ & $27.5(15.8-45.5)$ & 9.7 & 3.4 & 2.7 \\
\hline Total $(2034)$ & $28(15.8-50.6)$ & 11.8 & 4.3 & 2.9 \\
\hline
\end{tabular}

$P<0.05$; a: group versus DX. ${ }^{*} P<0.001$.

BMI: body mass index, CAD: coronary artery disease, CKD: chronic kidney disease, and DX: overhydration between -1.1 and $2.5 \mathrm{~L}$ with systolic blood pressure $100-150 \mathrm{mmHg}$.

0.001). In Region 3 increased BMI $28.6 \mathrm{~kg} / \mathrm{m}^{2}(P<0.001)$. In Region 4 increased incidence of CAD 13.6\%, $(P<0.001)$. (Table 4).

\section{Discussion}

Hypertension is a public health problem. According to recent meta-analysis including 966 patients with masked hypertension (MH) and 2640 healthy controls with sustained normotension, controlled hypertension, and white coat hypertension, the prevalence of LVH ranged from 7 to $66 \%$ in $\mathrm{MH}$ and from 0.4 to $42 \%$ in non-MH counterparts (average 29 versus 9\%, $P<0.01$ ) [12]. Definition of the special risk factors (genetics, dietary habits, and life style), leading causes, and early diagnosis are important for prevention of the disease for individual population.

Bioelectrical impedance spectroscopy is a noninvasive, inexpensive, and portable method that has been used mainly for body-composition analysis over the past decade. It is a suitable tool for large epidemiological studies. Our data showed that high blood pressure subjects had increased 


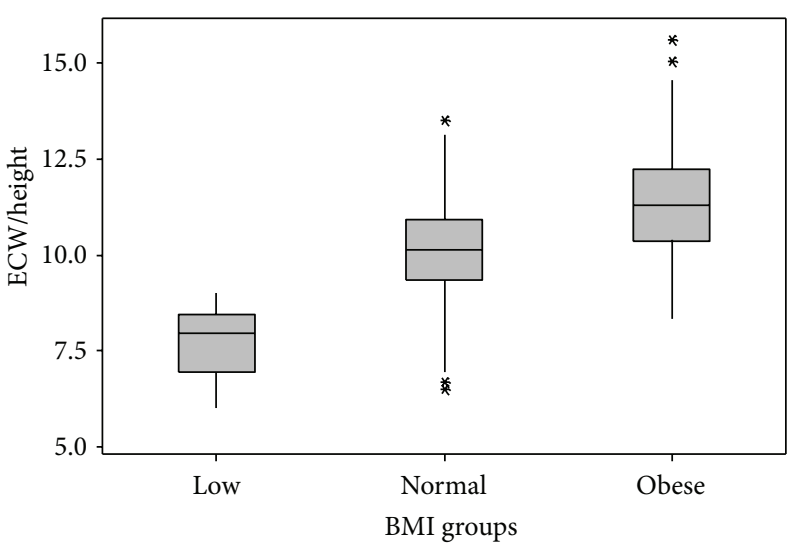

(a)

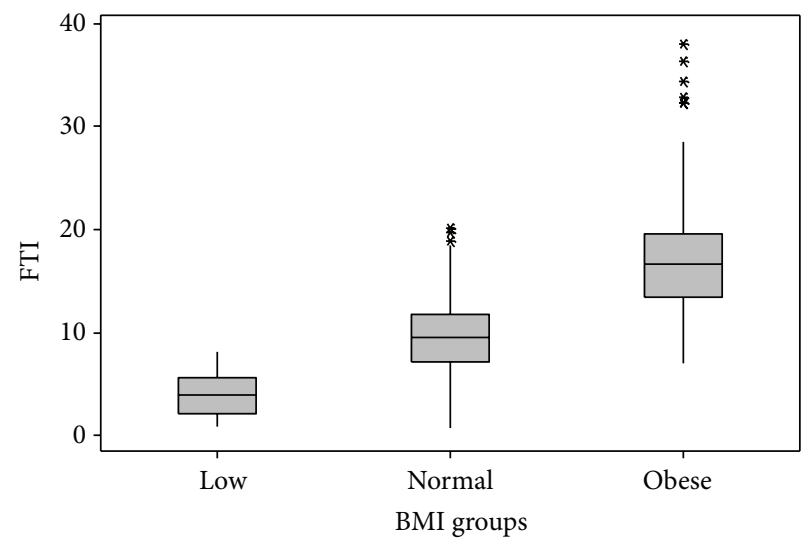

(b)

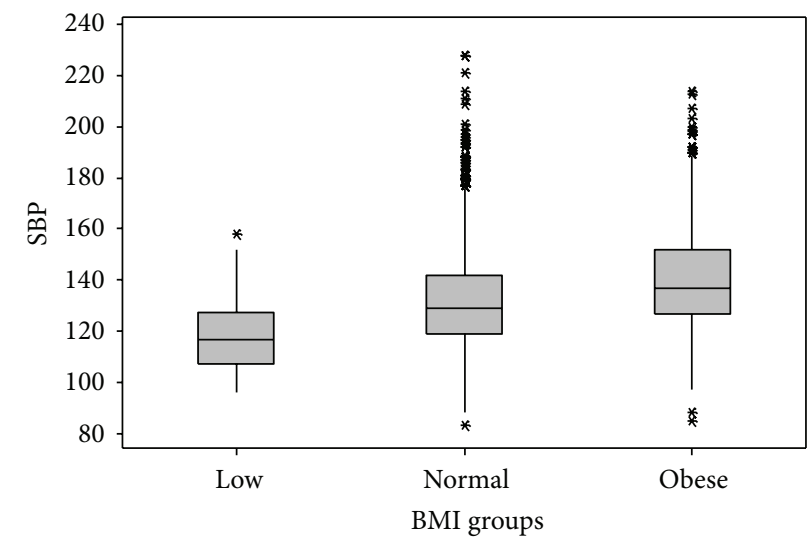

(c)

FIGURE 1: Obesity related with hydration fat tissue index and systolic blood pressure. $P<0.001$ between all groups. ECW: extracellular water/height $\left(\mathrm{L} / \mathrm{m}^{2}\right)$, FTI: fat tissue index $\left(\mathrm{kg} / \mathrm{m}^{2}\right)$, SBP: systolic blood pressure $(\mathrm{mmHg})$, and BMI: body mass index $\left(\mathrm{kg} / \mathrm{m}^{2}\right)$.

volume parameters which are consistent with previous observations [13-16].

In present study $\mathrm{E} / \mathrm{I}$ was higher in hypertensive group. But we know that E/I could be affected by changes in ICW as well as by ECW varying with hydration. This may lead to the spurious impression of overhydration in subjects with smaller ICW volumes so it does not reflect hydration alone [17]. Therefore we used other methods of expressing ECW as a measure of hydration.

Bomback et al. has reported that kidney handicap results in an altered aldosterone-ECV relationship that extends into the general population having negative volume, load, and inflammatory effects [18-20]. The expanded ECW in haemodialysis patients and the markedly elevated aldosterone levels seen in ESRD [18]. Low-dose mineralocorticoid receptor blocker therapy which provided better control of subclinical ECW expansion may attenuate the adverse effects of this receptor activation [19]. In obesity aldosterone level elevation and extracellular volume expansion are crucial for renal disease via aldosterone's nonepithelial, profibrotic, and proinflammatory effects [20]. In present study BMI highly correlated with FTI measured by bioimpedance. Obese people have significantly higher SBP than normal and low BMI group. Tagliabue et al. investigated the differences in the relationship between multifrequency impedance and body-water compartments (total body water (TBW) and extracellular water (ECW)) measured by dilution techniques in Italian and Dutch healthy subjects aged 19-41 years. In body build between the two groups, the main differences were height, trunk length, and the two ratios TBW/height and ECW/height. Population-specific prediction formulas for ECW (at $1 \mathrm{kHz}$ ) and TBW (at $100 \mathrm{kHz}$ ) were developed. The prediction errors for ECW and TBW were about 0.6 and $1.5 \mathrm{~kg}$, respectively, in both groups. They concluded that the water distribution between the extra- and intracellular compartments was the major cause of error in the prediction of body water, and in particular of ECW from impedance measurements with a population-specific equation [21]. Deurenberg et al. found that different, more slender body build leads to overestimation of ECW of the Ethiopian population. That study indicated that the validity of predicted body water from impedance depends on the body build of the subjects, which should be taken into account to avoid systematic errors when applying prediction formulas from a reference population to another population under study [22]. Bartz et al. showed ECW measured by multifrequency impedance was underestimated in males and slightly overestimated in females of Indonesian people and 


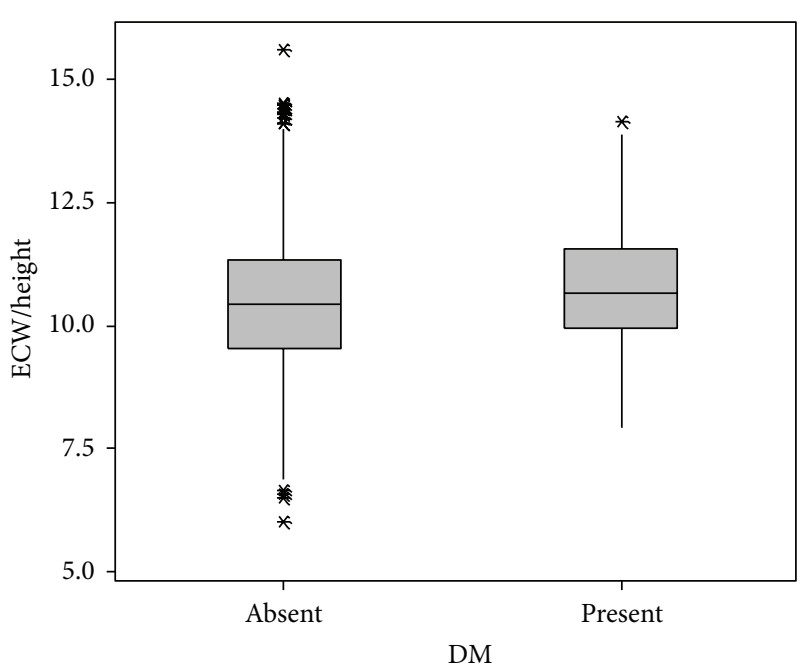

(a)

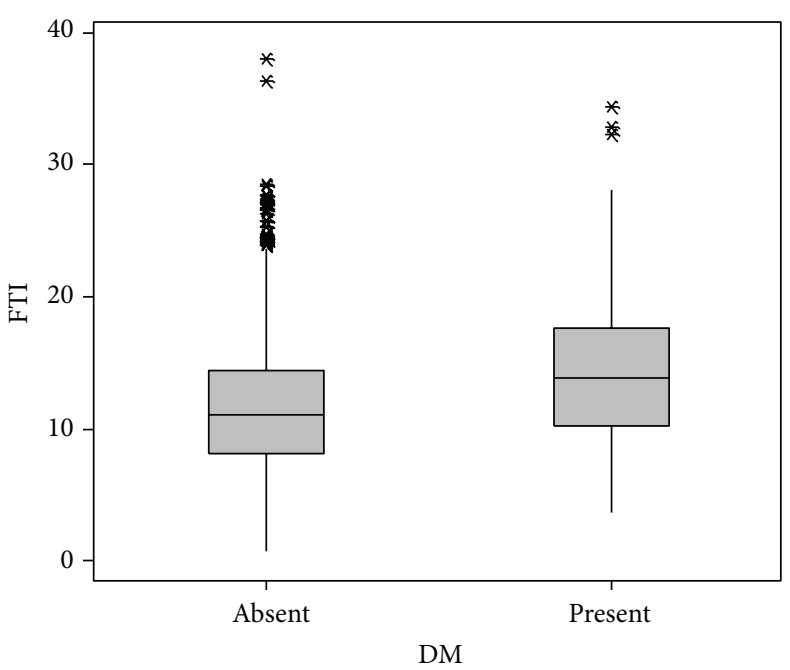

(b)

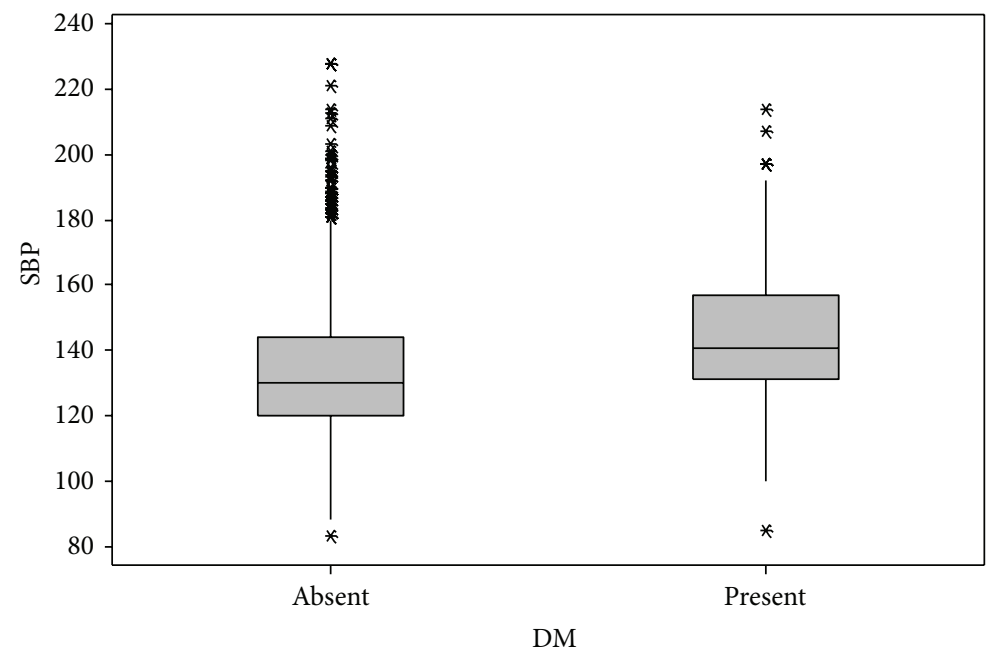

(c)

Figure 2: Diabetes mellitus related to hydration fat tissue index and systolic blood pressure. $P<0.001$ between all groups. ECW: extracellular water/height $\left(\mathrm{L} / \mathrm{m}^{2}\right)$, FTI: fat tissue index $\left(\mathrm{kg} / \mathrm{m}^{2}\right)$, SBP: systolic blood pressure $(\mathrm{mmHg})$, and BMI: body mass index $\left(\mathrm{kg} / \mathrm{m}^{2}\right)$.

concluded that the validation in a larger group of related population subjects was needed [23]. But at the same time it has been discovered that $\mathrm{OH}$, as determined by ECW/Ht, is highly predictive of clinical disease. ECW/height correlated well with volume overload as assessed by echocardiography in PD patients [24,25]. In the present study there was no obvious relationship between $\mathrm{OH}$ and blood pressure, but this might be expected because $\mathrm{OH}$ is calculated from the difference between the measured ECW and that expected which refer to patients of same age and sex, but they do not take into account racial differences.

A decrease in vascular compliance, such as what occurs with aging in larger blood vessels such as the aorta, may also contribute to the development of isolated systolic hypertension. Even in these conditions, however, it is quite possible that the kidney plays a role in maintaining the hypertensive response [26]. In present study we also found that advanced age and diabetic groups have high blood pressure.

Visser et al. showed that young healthy men with a higher BMI are associated with a larger increase in ECW during high salt intake, suggesting that altered sodium and fluid handling may be an early phenomenon in the pathophysiological consequences of weight excess and that dietary sodium restriction may have preventive potential in overweight subjects [27]. In present study BMI and FTI were higher in high blood pressure group. For every $10 \%$ increase in body fat, $\mathrm{OH}$ decreased by $1.2 \mathrm{~L}$; obesity seems to afford some protection aginst $\mathrm{OH}$ in dialysis patients [28].

In present study high blood pressure group have lower GFR measured by MDRD. In the literature the relation of ECW increase and a positive correlation between ECW and HT in patients with poor renal function were demonstrated 


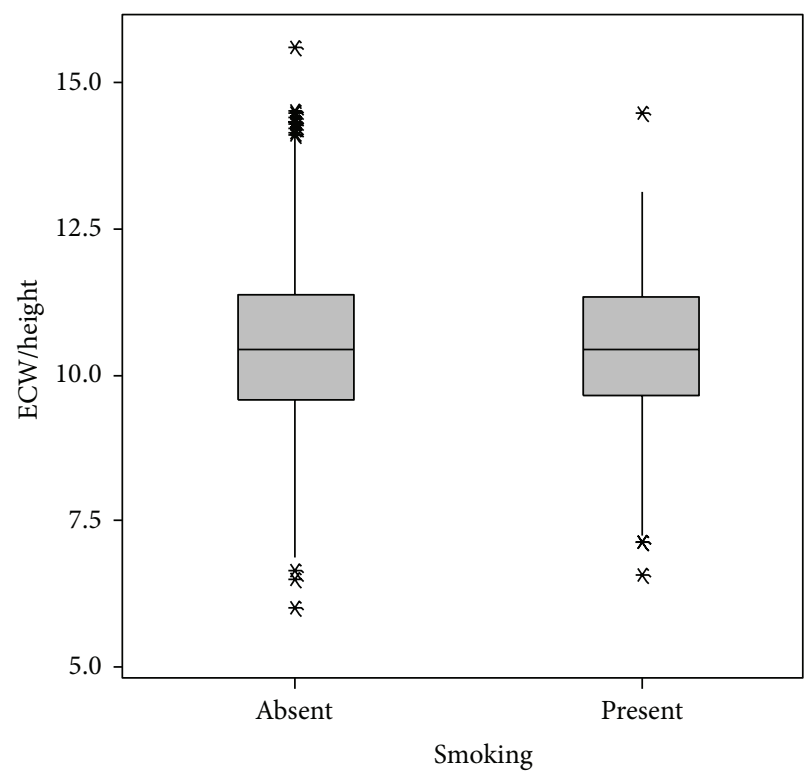

(a)

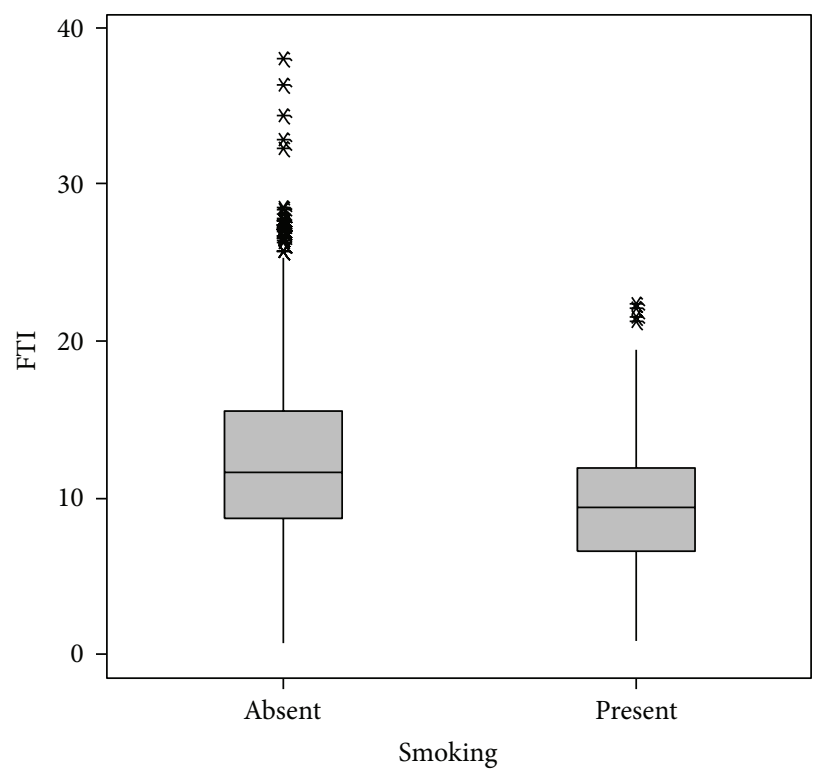

(b)

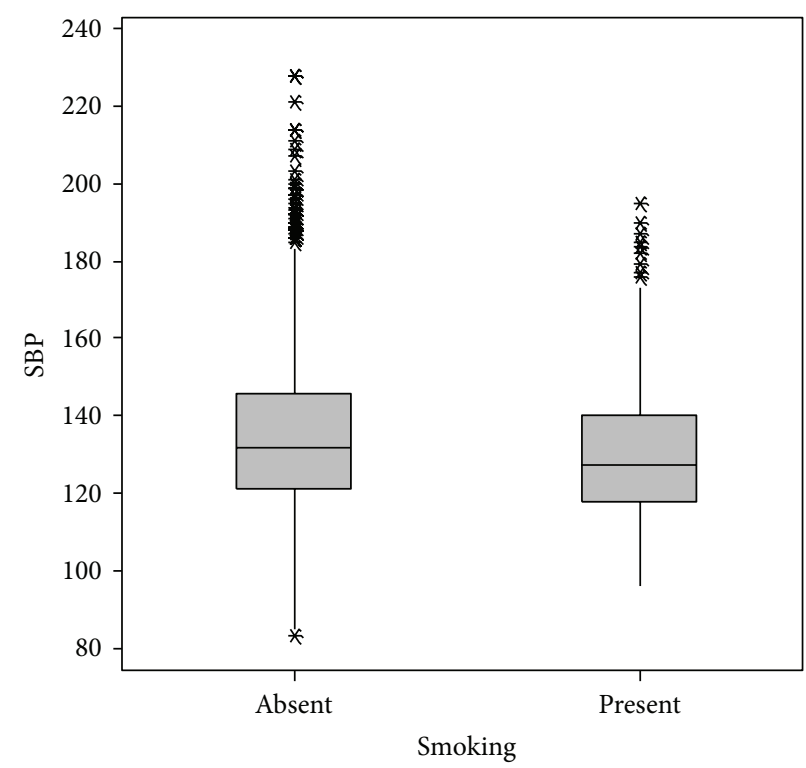

(c)

FIGURE 3: Smoking related to hydration fat tissue index and systolic blood pressure. $P<0.001$ for FTI and SBP. ECW: extracellular water/height $\left(\mathrm{L} / \mathrm{m}^{2}\right)$, FTI: fat tissue index $\left(\mathrm{kg} / \mathrm{m}^{2}\right)$, SBP: systolic blood pressure $(\mathrm{mmHg})$, and BMI: body mass index $\left(\mathrm{kg} / \mathrm{m}^{2}\right)$.

$[29,30]$. Recently we also demonstrated the strong positive correlation of increased ECW and hypertension in peritoneal dialysis patients [25].

Diabetes history, smoking, and bioimpedance measurement time afternoon were all associated with increased ECW. Brizzolara et al. demonstrated that poor glucose control positively correlated with ECW and E/I ratio [31]. These observations proving that good or moderate longterm control IDDM patients have proportionately normal distributions of ECW and ICW excess. Osmotic effect of glucose may be responsible.
A causal relationship between exposure to smoking and increase in blood pressure (BP) is not yet clearly demonstrated [32]. In a study 2742 Turkish adults prospectively evaluated for more than 7 years revealed that current cigarette smoking played a protective role at borderline significance but former smokers uniformly exhibited significantly higher risk for the development of hypertension. In our study we took only currently smoking cases as smokers, so lower blood pressure in smokers may be due to current smokers [33]. Fat tissue index was also found less than expected in smokers. 


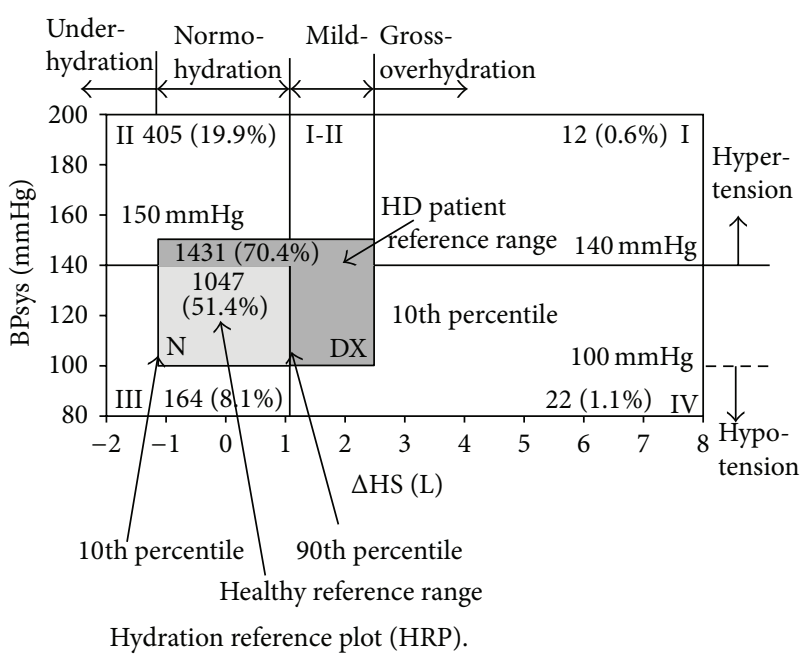

FIGURE 4: Hydration reference plot.

In present study for the cut-off value $10.06 \mathrm{~L} / \mathrm{m}$ of ECW/height; high blood pressure predicted positively in $69 \%$ and excluded in $45 \%$.

To our knowledge, there were no such studies comparing the effect of time period on bioimpedance measurement. We revealed that afternoon measurements were associated with increased $\mathrm{OH}$, may be due to circadian rhythm of cortisone or likely whole body measurements [34]. The other reason may be the fluid shifts to the extremities during standing. It is better to tailor bioimpedance measurement protocols accordingly after such epidemiological studies.

Although the cross-sectional design of our study and other limitations preclude to infer a causal relationship between high blood pressure and ECW/height ratio, increased age and BMI and diabetes history. All these risk factors must be taken into consideration for hypertension.

There is no satisfying explanation of changes of body water composition in high blood pressure. BIS a noninvasive, cheap, and easily repeatable method has the potential to improve the etiology and management of the various hypertensive states in the majority of patients all over the world.

Bioelectrical impedance analysis is a practical method for the followup of antihypertensive therapy in pregnancy [35] and in the future it might be used for all hypertensive subjects evaluating the effectiveness of pharmacological treatments by means of volume restoration accordingly.

Expected $\mathrm{OH}$ in the $\mathrm{BCM}$ device used is setup from a largely Caucasian population, but it remains to be demonstrated whether there are differences in hydration status in different ethnic groups. In the Turkish population however the results indicate no bias in hydration when measured with BCM. So other population studies will be needed in this field.

More than half of the studied population is in " $\mathrm{N}$ " region of the hydration reference (Wabel plot). Most of the cases are in DX region (includes $\mathrm{N}$ region) 70.4\%. Region 1 (overhydrated-hypertensives) composed of a minor group of population $(0.6 \%)$ and having statistically significant DM and absence of CAD. Hypertension may be volume dependent just as seen in most dialysis patients. In this group hypertension treatment strategy must be adjusted towards diuretics. Region 2 (normo/hypovolemic-hypertensives) composed of nearly $1 / 5$ of the population and having statistically significant $\mathrm{DM}, \mathrm{CAD}$ and obese cases in this group. Etiology of hypertension seems as volume independent and may be speculated as rennin dependent. Accordingly angiotensin converting enzyme inhibitors and angiotensin receptor blockers might be the first choice for probable etiology and related comorbidities. Region 3 (underhydrated-normal/low SBP) composed of $8.1 \%$ of whole population with increased number of obesity. Region 4 (overhydrated-normo/hypotensives) composed of $1.1 \%$ of population with increase incidence of CAD. This group needs further cardiac evaluation for congestive heart diseases and salt restriction must be logical approach for such cases.

Normal BP in the presence of overhydration would also be an important group to identify/screen to target treatment strategies appropriately. Hypertensive subjects who are not overhydrated would likely need different treatment strategies also. Measuring BP and hydration and taking into account the traditional risk factors may allow for better diagnosis and treatment. Blood pressure and hydration can be measured readily and this could help to direct the line of investigation in the search for primary causes.

High blood pressure may be accompanied by increased extracellular volume indices. In the future volume status assessment could be of use in evaluating the effectiveness of pharmacological intervention in the treatment of hypertension.

\section{Conflict of Interests}

The authors declare that there is no conflict of interests regarding the publication of this paper.

\section{Acknowledgments}

The authors would like to thank James R. Matthie and Klemmer PJ for their critical review of the paper.

\section{References}

[1] A. C. Guyton, T. G. Coleman, A. W. Cowley, K. W. Scheel, R. D. Manning, and R. A. Norman, "Arterial pressure regulation. Overriding dominance of the kidneys in long-term regulation and in hypertension," The American Journal of Medicine, vol. 52, no. 5, pp. 584-594, 1972.

[2] M. A. Alvarez-Lara, A. Martín-Malo, M. Espinosa, A. Rodríguez-Benot, and P. Aljama, "Blood pressure and body water distribution in chronic renal failure patients," Nephrology Dialysis Transplantation, vol. 16, no. 1, pp. 94-97, 2001.

[3] U. M. Moissl, P. Wabel, P. W. Chamney et al., "Body fluid volume determination via body composition spectroscopy in health and disease," Physiological Measurement, vol. 27, no. 9, article 012, pp. 921-933, 2006.

[4] P. W. Chamney, P. Wabel, U. M. Moissl et al., "A whole-body model to distinguish excess fluid from the hydration of major 
body tissues," The American Journal of Clinical Nutrition, vol. 85, no. 1, pp. 80-89, 2007.

[5] W. van Biesen, J. D. Williams, A. C. Covic et al., "Fluid status in peritoneal dialysis patients: the European body composition monitoring (EuroBCM) study cohort," PLoS ONE, vol. 6, no. 2, Article ID e17148, 2011.

[6] E. Hur, M. Usta, H. Toz et al., "Effect of fluid management guided by bioimpedance spectroscopy on cardiovascular parameters in hemodialysis patients: a randomized controlled trial," American Journal of Kidney Diseases, vol. 61, no. 6, pp. 957-965, 2013.

[7] V. Wizemann, P. Wabel, P. Chamney et al., "The mortality risk of overhydration in haemodialysis patients," Nephrology Dialysis Transplantation, vol. 24, no. 5, pp. 1574-1579, 2009.

[8] P. Wabel, U. Moissl, P. Chamney et al., "Towards improved cardiovascular management: the necessity of combining blood pressure and fluid overload," Nephrology Dialysis Transplantation, vol. 23, no. 9, pp. 2965-2971, 2008.

[9] J. Coresh, B. C. Astor, T. Greene, G. Eknoyan, and A. S. Levey, "Prevalence of chronic kidney disease and decreased kidney function in the adult US population: third national health and nutrition examination survey," American Journal of Kidney Diseases, vol. 41, no. 1, pp. 1-12, 2003.

[10] A. S. Levey, J. P. Bosch, J. B. Lewis, T. Greene, N. Rogers, and D. Roth, "A more accurate method to estimate glomerular filtration rate from serum creatinine: a new prediction equation," Annals of Internal Medicine, vol. 130, no. 6, pp. 461-470, 1999.

[11] S. Wieskotten, S. Heinke, P. Wabel et al., "Bioimpedance-based identification of malnutrition using fuzzy logic," Physiological Measurement, vol. 29, no. 5, pp. 639-654, 2008.

[12] C. Cuspidi, F. Negri, C. Sala, and G. Mancia, "Masked hypertension and echocardiographic left ventricular hypertrophy: an updated overview," Blood Pressure Monitoring, vol. 17, no. 1, pp. 8-13, 2012.

[13] J. H. Bauer and C. S. Brooks, "Volume studies in men with mild to moderate hypertension," The American Journal of Cardiology, vol. 44, no. 6, pp. 1163-1170, 1979.

[14] J. H. Bauer and C. S. Brooks, "Body-fluid composition in normal and hypertensive man," Clinical Science, vol. 62, no. 1, pp. 43-49, 1982.

[15] R. P. Garay, G. Dagher, and P. Meyer, "An inherited sodium ionpotassium ion cotransport defect in essential hypertension," Clinical Science, vol. 59, no. 6, pp. 191-193, 1980.

[16] H. Ibsen and A. Leth, "Plasma volume and extracellular fluid volume in essential hypertension," Acta Medica Scandinavica, vol. 194, no. 1-2, pp. 93-96, 1973.

[17] G. Woodrow, B. Oldroyd, A. Wright, W. A. Coward, and J. G. Truscott, "The effect of normalization of ECW volume as a marker of hydration in peritoneal dialysis patients and controls," Peritoneal Dialysis International, vol. 25, no. 3, pp. S49-S51, 2005.

[18] A. S. Bomback, A. V. Kshirsagar, M. E. Ferris, and P. J. Klemmer, "Disordered aldosterone-volume relationship in end-stage kidney disease," Journal of the Renin-Angiotensin-Aldosterone System, vol. 10, no. 4, pp. 230-236, 2009.

[19] A. S. Bomback and P. J. Klemmer, "Mineralocorticoid receptor blockade in chronic kidney disease," Blood Purification, vol. 33, no. 1-3, pp. 119-124, 2012.

[20] A. S. Bomback and P. J. Klemmer, "Interaction of aldosterone and extracellular volume in the pathogenesis of obesityassociated kidney disease: a narrative review," American Journal of Nephrology, vol. 30, no. 2, pp. 140-146, 2009.
[21] A. Tagliabue, H. Cena, and P. Deurenberg, "Comparative study of the relationship between multi-frequency impedance and body water compartments in two European populations," British Journal of Nutrition, vol. 75, no. 1, pp. 11-19, 1996.

[22] P. Deurenberg, Z. Wolde-gebriel, and F. J. M. Schouten, "Validity of predicted total body water and extracellular water using multifrequency bioelectrical impedance in an Ethiopian population," Annals of Nutrition and Metabolism, vol. 39, no. 4, pp. 234-241, 1995.

[23] M. Bartz, J. Küpper, W. Schultink, W. Lukito, and P. Deurenberg, "Validation of predicted total body water and extracellular water by multi-frequency impedance in young Indonesian adults," Annals of Nutrition and Metabolism, vol. 42, no. 3, pp. 119-126, 1998.

[24] M. S. Demirci, C. Demirci, O. Ozdogan et al., "Relations between malnutrition-inflammation-atherosclerosis and volume status. The usefulness of bioimpedance analysis in peritoneal dialysis patients," Nephrology Dialysis Transplantation, vol. 26, no. 5, pp. 1708-1716, 2011.

[25] E. Hur, O. Gungor, O. Musayev et al., "Bioimpedance spectroscopy for the detection of hypervolemia in peritoneal dialysis patients," Advances in Peritoneal Dialysis, vol. 27, pp. 65-70, 2011.

[26] R. J. Johnson, J. Herrera-Acosta, G. F. Schreiner, and B. Rodríguez-Iturb, "Subtle acquired renal injury as a mechanism of salt-sensitive hypertension," The New England Journal of Medicine, vol. 346, no. 12, pp. 913-923, 2002.

[27] F. W. Visser, J. A. Krikken, J. H. J. Muntinga, R. A. Dierckx, and G. J. Navis, "Rise in extracellular fluid volume during high sodium depends on bmi in healthy men," Obesity, vol. 17, no. 9, pp. 1684-1688, 2009.

[28] M. Tapolyai, M. Faludi, V. Réti, Z. Lengvárszky, T. Szarvas, and K. Berta, "Dialysis patients' fluid overload, antihypertensive medications, and obesity," ASAIO Journal, vol. 57, no. 6, pp. 511515, 2011.

[29] H. A. Koomans, J. C. Roos, P. Boer, G. G. Geyskes, and E. J. Mees, "Salt sensitivity of blood pressure in chronic renal failure. Evidence for renal control of body fluid distribution in man," Hypertension, vol. 4, no. 2, pp. 190-197, 1982.

[30] R. M. Fagugli, P. Pasini, G. Quintaliani et al., "Association between extracellular water, left ventricular mass and hypertension in haemodialysis patients," Nephrology Dialysis Transplantation, vol. 18, no. 11, pp. 2332-2338, 2003.

[31] A. Brizzolara, M. P. Barbieri, L. Adezati, and G. L. Viviani, "Water distribution in insulin-dependent diabetes mellitus in various states of metabolic control," European Journal of Endocrinology, vol. 135, no. 5, pp. 609-615, 1996.

[32] A. Leone, "Smoking and hypertension: independent or additive effects to determining vascular damage?" Current Vascular Pharmacology, vol. 9, no. 5, pp. 585-593, 2011.

[33] A. Onat, M. Uğur, G. Hergenç, G. Can, S. Ordu, and D. Dursunoğlu, "Lifestyle and metabolic determinants of incident hypertension, with special reference to cigarette smoking: a longitudinal population-based study," The American Journal of Hypertension, vol. 22, no. 2, pp. 156-162, 2009.

[34] L. Liu, F. Zhu, J. G Raimann et al., "Determination of fluid status in haemodialysis patients with whole body and calf bioimpedance techniques," Nephrology, vol. 17, no. 2, pp. 131-140, 2012.

[35] R. Yasuda, K. Takeuchi, T. Funakoshi, and T. Maruo, "Bioelectrical impedance analysis in the clinical management of preeclamptic women with edema," Journal of Perinatal Medicine, vol. 31, no. 4, pp. 275-280, 2003. 


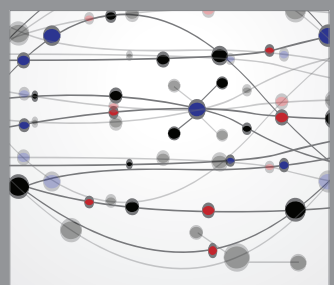

The Scientific World Journal
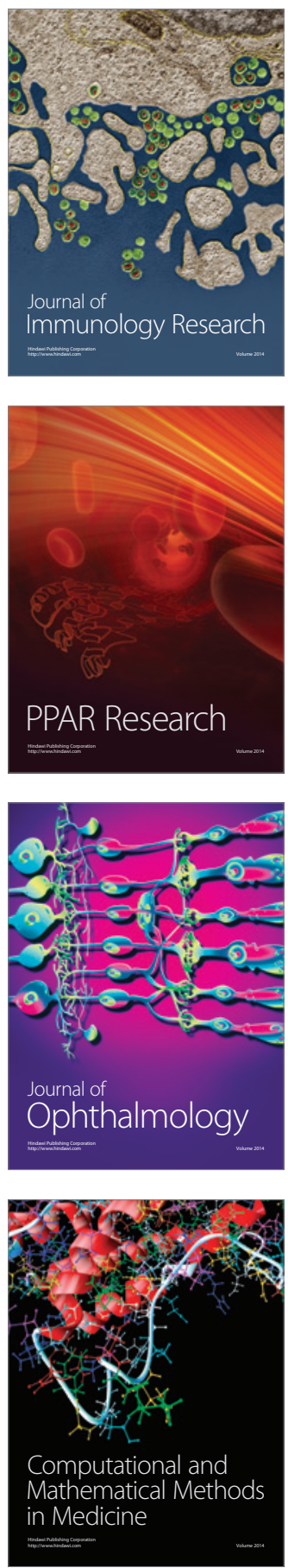

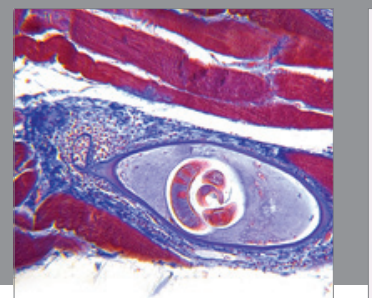

Gastroenterology

Research and Practice
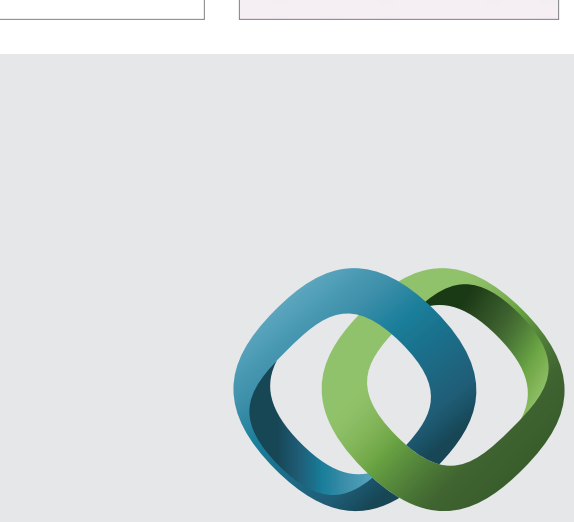

\section{Hindawi}

Submit your manuscripts at

http://www.hindawi.com
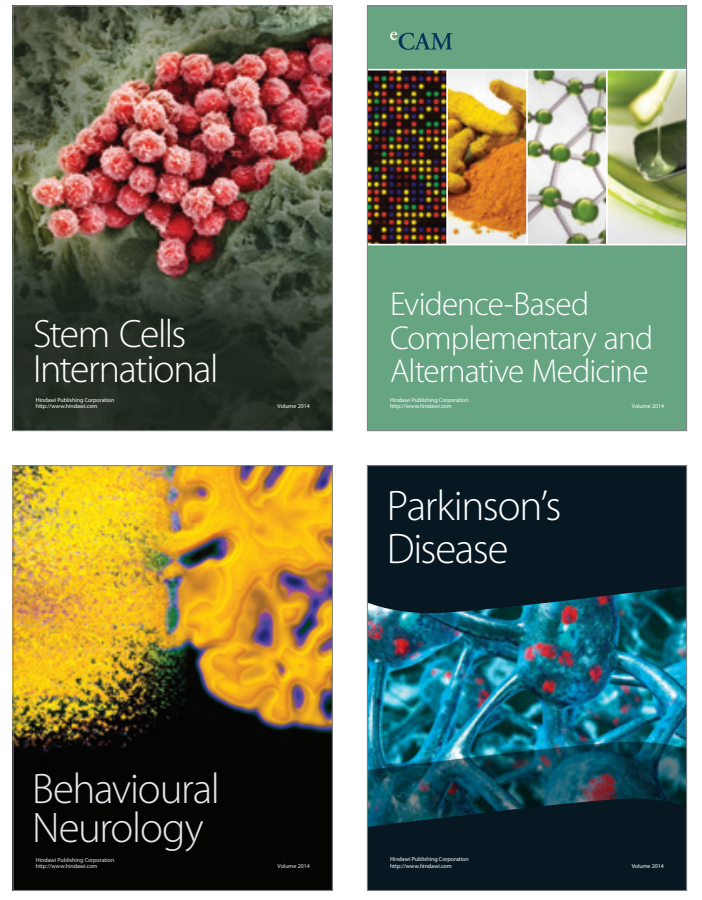
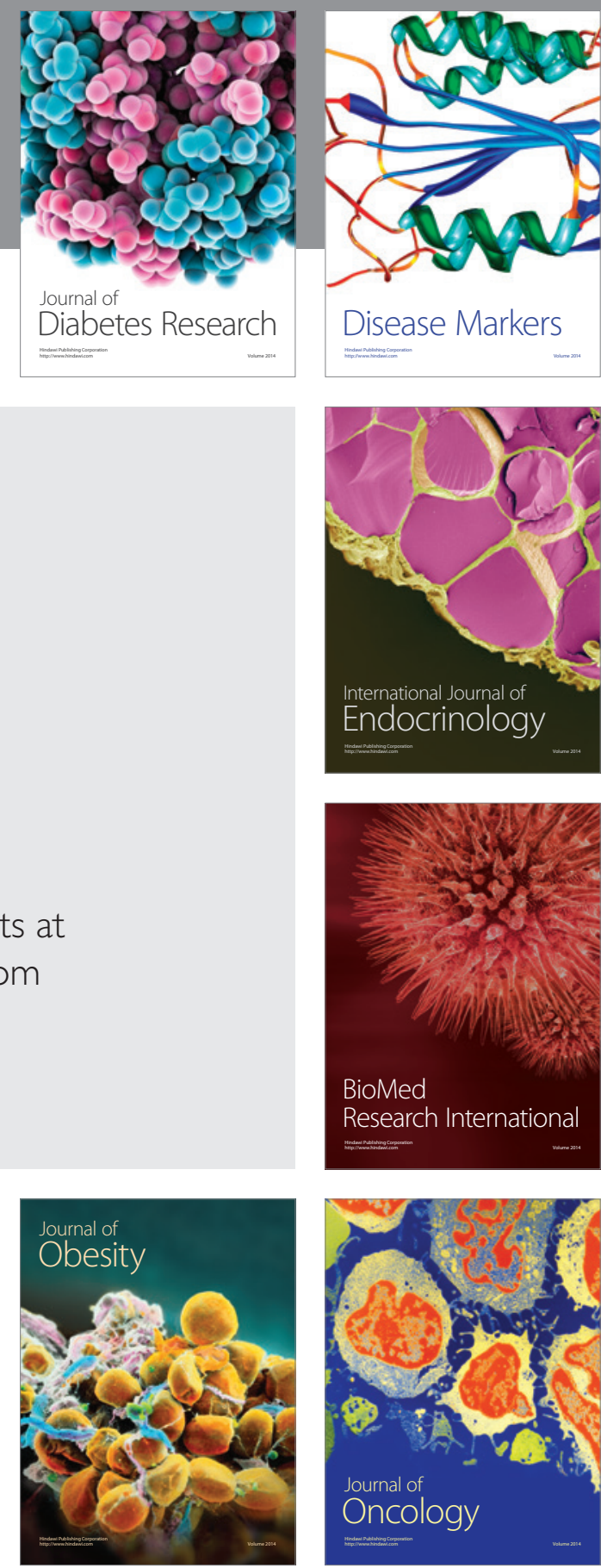

Disease Markers
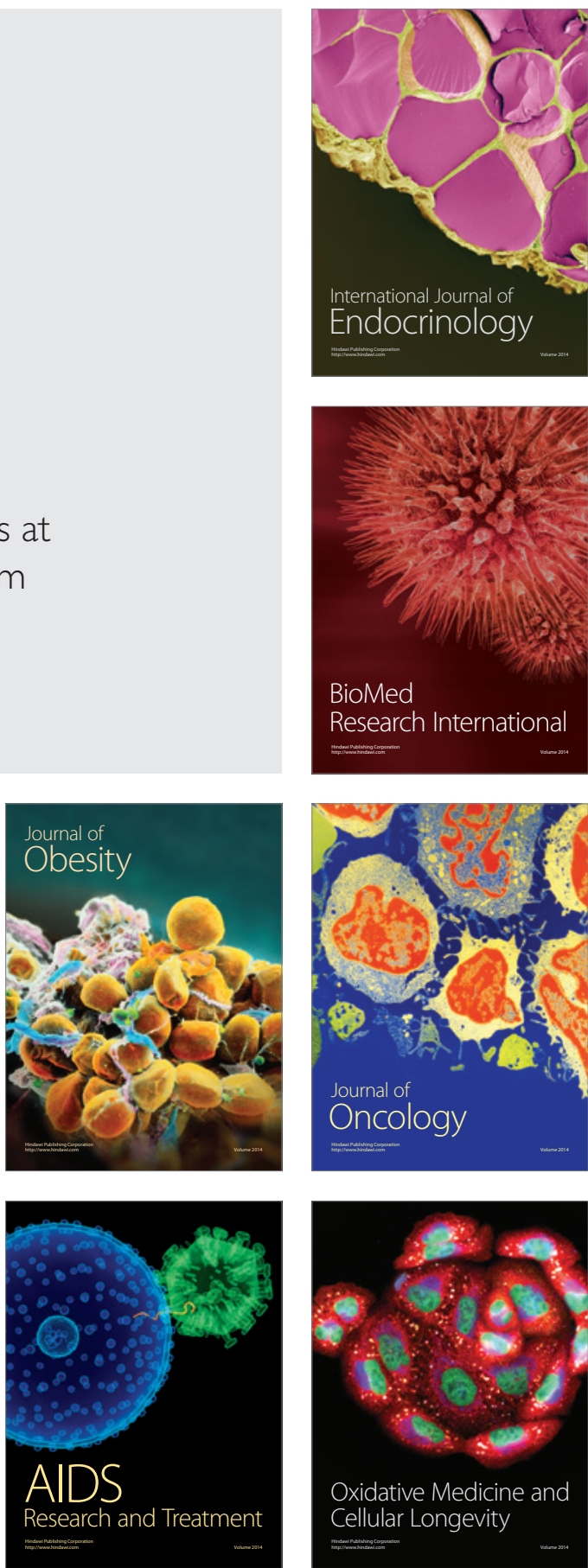